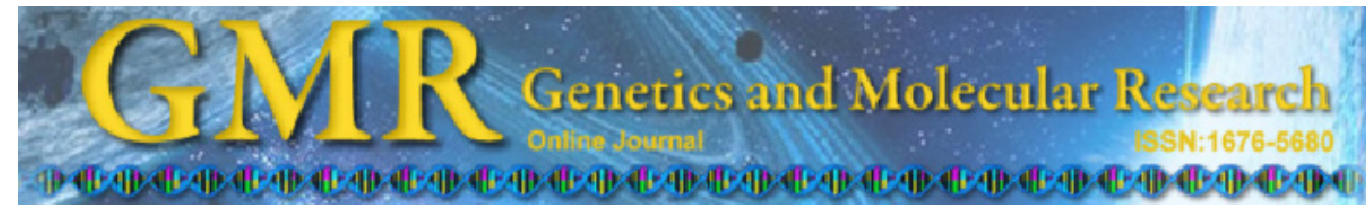

\title{
Use of simple sequence repeat markers for DNA fingerprinting and diversity analysis of sugarcane (Saccharum spp) cultivars resistant and susceptible to red rot
}

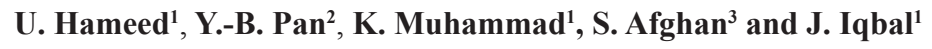 \\ ${ }^{1}$ School of Biological Sciences, University of the Punjab, Lahore, Pakistan \\ ${ }^{2}$ Sugarcane Research Laboratory, U.S. Department of Agriculture, \\ Agricultural Research Service, Houma, LA, USA \\ ${ }^{3}$ Shakarganj Sugar Research Institute, Jhang, Pakistan \\ Corresponding authors: J. Iqbal / Y.-B. Pan \\ E-mail: javediqbal1942@yahoo.com / yongbao.pan@ars.usda.gov
}

Genet. Mol. Res. 11 (2): 1195-1204 (2012)

Received March 10, 2011

Accepted January 16, 2012

Published May 8, 2012

DOI http://dx.doi.org/10.4238/2012.May.8.1

\begin{abstract}
Red rod is an economically important disease of sugarcane caused by the fungus Colletotrichum falcatum. We used a simple sequence repeat (SSR)-based marker system to identify and analyze genetic relationships of red rot resistant and susceptible sugarcane cultivars grown in Pakistan. Twenty-one highly polymorphic SSR markers were used for DNA fingerprinting and genetic diversity analysis of 20 sugarcane cultivars. These SSR markers were found to be highly robust; we identified 144 alleles, with 3-11 alleles per marker and a mean of 6.8 . Three SSR markers were able to identify all 20 cultivars. DNAMAN ${ }^{\circledR}$-generated homology tree was used to analyze genetic diversity among these cultivars; all cultivars shared $58 \%$ or more similarity. We correlated polymorphism information content and resolving power values with marker effectiveness in the process of sugarcane cultivar identification. We concluded that a small number
\end{abstract}


of SSR-derived DNA markers will allow breeders to identify red rot resistant and susceptible cultivars.

Key words: Sugarcane; Simple sequence repeat; Genetic identity; Polymerase chain reaction

\section{INTRODUCTION}

Modern sugarcane cultivars are interspecific hybrids produced by crosses between $\mathrm{Sac}$ charum officinarum L. and its wild relatives S. spontaneum L., S. sinense Roxb. or S. barberi Jesw (Miller et al., 2005). Sugarcane cultivars have a complex, aneuploid and polyploid genome, which contains 100-120 chromosomes (D'Hont et al., 1996). Due to the complex nature of the genome, molecular analysis of sugarcane is not an easy task; however, different molecular techniques have been employed in sugarcane breeding and trait-related marker studies, including random amplified polymorphic DNA (RAPD) for genetic diversity (Harvey and Botha, 1996; Nair et al., 2002; Pan et al., 2003a), amplified fragment length polymorphism (AFLP) for genome mapping and QTL analysis of yield components (Hoarau et al., 2002; Lima et al., 2002), and restriction fragment length polymorphism (RFLP) in genetic diversity and genome complexity (Lu et al., 1994; Jannoo et al., 1999; Silva and Bressiani, 2005).

Present in the genomes of most eukaryotic organisms, microsatellites or simple sequence repeats (SSRs) are short nucleotide repeats of 1-6 bp with SSR alleles showing differences in the number of these repeat units (Jeffreys et al., 1985). SSR markers are ubiquitous in plant genome and have advantage of reproducibility and multiallelism (Powell et al., 1996). SSR marker studies have been carried out in different plant species such as maize (Sharopova et al., 2002), rice (Chen et al., 1997), wheat (Pestsova et al., 2000), and barley (Liu et al., 1996). A large amount of variability was found among different species and populations (Goldstein and Schlotterer, 1999). Due to this variability, microsatellite markers have been used for different genetic studies. Specifically for sugarcane, it is worthwhile to mention studies such as fingerprinting of Australian sugarcane clones (Piperidis et al., 2001), genotyping and fingerprinting of USA sugarcane cultivars (Pan et al., 2003a,b; Glynn et al., 2009), genetic diversity (Cordeiro et al., 2003), mapping of useful genes (Singh et al., 2005), genetic mapping (Garcia et al., 2006), sugarcane genome study (Garcia et al., 2006), cultivar identification (Pan et al., 2007), evolutionary relationships among species (Brown et al., 2007), use of EST-derived SSR for fingerprinting (Pinto et al., 2006), marker assisted selection (Pinto et al., 2011), etc. With the advances of sugarcane microsatellite (SSR) DNA genotyping technology, the sugarcane breeders are now able to efficiently and accurately determine the genetic identity of sugarcane varieties and reveal any sugarcane clone misidentifications (Pan et al., 2003a,b). The International Sugarcane Microsatellite Consortium (ISMC) has designed 221 microsatellite markers based on the sugarcane genomic DNA sequences (Cordeiro et al., 2000). In 2006, Pan et al. used these 221 microsatellite markers for germplasm evaluation and fingerprinting of USA cultivars. They found that 67 of these 221 markers showed robust PCR products. Based on the study of Pan et al. (2006), we selected 21 highly polymorphic microsatellite markers to genotype 20 sugarcane cultivars grown in Pakistan.

The objectives of the present research were: a) to develop molecular identification profiles, based on SSR markers, of 20 sugarcane cultivars resistant/susceptible to red rot dis- 
ease from Pakistan, so that the breeder can identify these cultivars correctly; b) to analyze their genetic diversity.

\section{MATERIAL AND METHODS}

\section{Plant material}

Twenty sugarcane cultivars that are grown mainly in Pakistan were obtained from the Shakarganj Sugar Research Institute (SSRI), Jhang, Pakistan. These cultivars showed different disease responses to the red rot pathogen that varied from highly resistant to highly susceptible (Table 1). Other parameters for the selection of these genotypes also included characteristics such as yield potential, maturity trend, ratoonability, salt tolerance, etc. (data not shown).

\begin{tabular}{|c|c|c|c|}
\hline Serial number & Genotype & Parents & Response to red rot \\
\hline 1 & HSF 240 & CP43-33 $\times$ Open pollination & Highly resistant \\
\hline 2 & CPF237 & $86 \mathrm{P}-19 \times \mathrm{CP} 70-1133$ & Highly resistant \\
\hline 3 & NSG555 & $\mathrm{CP} 63-588 \times \mathrm{MO} / \mathrm{F}$ & Highly resistant \\
\hline 4 & CSSG676 & ROC-1 1 CP74-2005 & Highly resistant \\
\hline 5 & NSG311 & $\mathrm{N} 19 \times \mathrm{MO} / \mathrm{F}$ & Resistant \\
\hline 6 & HoSG529 & CP89-885 × LCP86-454 & Resistant \\
\hline 7 & SPSG26 & SP73-5368 × SP70-1143 & Resistant \\
\hline 8 & CPF246 & US90-1093 × CP81-1425 & Resistant \\
\hline 9 & CP77/400 & Not known & Resistant \\
\hline 10 & SPSG79 & SP70-1143 × SP73-5368 & Resistant \\
\hline 11 & NSG59 & $91 \mathrm{~W} 0510 \times 82 \mathrm{~F} 0542$ & Resistant \\
\hline 12 & CPD334 & НоСР85-845 × Ho93-769 & Resistant \\
\hline 13 & SPF213 & SP70-1006 $\times$ Open pollination & Moderately resistant \\
\hline 14 & CPD335 & US95-1038 $\times$ US95-1014 & Moderately resistant \\
\hline 15 & CPSG2453 & MQ87-1215 × 86A3626 & Moderately resistant \\
\hline 16 & CPD346 & CP78-1628 × CP92-1320 & Moderately susceptible \\
\hline 17 & Co1148 & Co-301 × P-4383 & Susceptible \\
\hline 18 & HSF242 & SPSH89-2085 × Poly cross & Susceptible \\
\hline 19 & SPSG394 & N5679 $\times$ SP70-1143 & Susceptible \\
\hline 20 & SPF234 & SP71-8210 × SP71-6180 & Susceptible \\
\hline
\end{tabular}

\section{DNA extraction}

Total genomic DNA was isolated from fresh leaf samples by the CTAB method (Doyle and Doyle, 1990). DNA concentrations were quantified by UV spectrophotometry followed by equilibration by $1.5 \%$ (w/v) agarose gel electrophoresis (Sambrook et al., 1989).

\section{PCR amplification and capillary electrophoresis (CE)}

PCR and SSR fragment analysis were conducted following a high-throughput sugarcane genotyping procedure (Pan et al., 2007), in which a Hamilton's Microlab Star Liquid Handling Station with a 96 probe head and eight independent pipette channels (Hamilton Company, Reno, NV, USA) were used to prepare PCR and CE samples. The 
PCR volume was $5 \mu \mathrm{L}$ consisting of $0.25 \mu \mathrm{L}$ DNA sample, $0.5 \mu \mathrm{L} 10 \mathrm{X}$ buffer, $0.3 \mu \mathrm{L} 25$ $\mathrm{mM} \mathrm{MgCl}, 0.1 \mu \mathrm{L} 10 \mathrm{mM}$ dNTPs, $0.41 \mu \mathrm{L} 3 \mu \mathrm{M}$ of each forward and reverse primers, 0.5 $\mu \mathrm{L} 10 \mathrm{mg} / \mathrm{mL}$ BSA-V, $0.5 \mu \mathrm{L} 100 \mathrm{mg} / \mathrm{mL}$ PVP-40, $0.025 \mu \mathrm{L} 5 \mathrm{U} / \mu \mathrm{L}$ Taq polymerase and 2.0 $\mu \mathrm{L}$ PCR water. PCR amplifications were conducted on a DNA Engine Tetra (Bio-Rad Laboratories, Hercules, CA, USA) under the program of $95^{\circ} \mathrm{C}$ for $15 \mathrm{~min}, 40$ cycles of $94^{\circ} \mathrm{C}$ for $15 \mathrm{~s}$, varying annealing temperature (Table 2) for $15 \mathrm{~s}$, and $72^{\circ} \mathrm{C}$ for $1 \mathrm{~min}$, a final extension at $72^{\circ} \mathrm{C}$ for $10 \mathrm{~min}$, and holding at $4^{\circ} \mathrm{C}$. PCR-amplified SSR DNA fragments were separated along with the GeneScan ${ }^{\mathrm{TM}} 500$ Rox $^{\mathrm{TM}}$ Size Standard by CE on an ABI3730 Genetic Analyzer, a procedure called GeneScan or fragment analysis, following manufacturer instructions (Applied Biosystems, Inc., Foster City, CA, USA). The CE-based separation processes were recorded automatically into individual GeneScan files.

\begin{tabular}{|c|c|c|c|c|c|}
\hline Number & SSR name & Repeat motif & $\begin{array}{l}\text { Forward primer sequence }\left(5^{\prime}-3^{\prime}\right) \\
\text { Reverse primer sequence }\left(5^{\prime}-3^{\prime}\right)\end{array}$ & Annealing temperature & $\begin{array}{c}\text { No. of amplified } \\
\text { alleles }\end{array}$ \\
\hline 1 & mSSCIR74 & $(\mathrm{CGC})_{9}$ & $\begin{array}{l}\text { GCGCAAGCCACACTGAGA } \\
\text { ACGCAACGCAAAACAACG }\end{array}$ & 54 & 5 \\
\hline 2 & SMC31CUQ & $(\mathrm{TC})_{10}(\mathrm{AC})_{22}$ & $\begin{array}{l}\text { CATGCCAACTTCCAATACAGACT } \\
\text { AGTGCCAATCCATCTCAGAGA }\end{array}$ & 62 & 11 \\
\hline 3 & mSSCIR66 & $(\mathrm{GT})_{43} \mathrm{GC}(\mathrm{GT})_{6}$ & $\begin{array}{l}\text { AGGTGATTTAGCAGCATA } \\
\text { CACAAATAAACCCAATGA }\end{array}$ & 48 & 4 \\
\hline 4 & mSSCIR43 & $(\mathrm{GT})_{3}(\mathrm{AT})_{2}(\mathrm{GT})_{29}$ & $\begin{array}{l}\text { ATTCAACGATTT TCACGAG } \\
\text { AACCTAGCAATTTACAAGAG }\end{array}$ & 52 & 9 \\
\hline 5 & SMC703BS & $(\mathrm{CA})_{12}$ & $\begin{array}{l}\text { GCCTTTCTCCAAACCAATTAGT } \\
\text { GTTGTTTATGGAATGGTGAGGA }\end{array}$ & 62 & 8 \\
\hline 6 & SMC851MS & $(\mathrm{AG})_{29}$ & $\begin{array}{l}\text { ACTAAAATGGCAAGGGTGGT } \\
\text { CGTGAGCCCACATATCATGC }\end{array}$ & 58 & 6 \\
\hline 7 & SMC36BUQ & $(\mathrm{TTG})_{7}$ & $\begin{array}{l}\text { GGGTTTCATCTC TAGCCTACC } \\
\text { TCAGTAGCAGAGTCAGACGCTT }\end{array}$ & 64 & 3 \\
\hline 8 & SMC7CUQ & $(\mathrm{CA})_{10}(\mathrm{C})_{4}$ & $\begin{array}{l}\text { GCCAAAGCAAGGGTCACTAGA } \\
\text { AGCTCTATCAGTTGAAACCGA }\end{array}$ & 60 & 6 \\
\hline 9 & SMC336BS & $(\mathrm{TG})_{23}(\mathrm{AG})_{19}$ & $\begin{array}{l}\text { ATTCTAGTGCCAATCCATCTCA } \\
\text { CATGCCAACTTCCAAACAGAC }\end{array}$ & 62 & 10 \\
\hline 10 & SMC22DUQ & $(\mathrm{CAG})_{5} \mathrm{C}(\mathrm{AGG})_{5}$ & $\begin{array}{l}\text { CCATTCGACGAAAGCGTCCT } \\
\text { CAAGCGTTGTGCTGCCGAGT }\end{array}$ & 62 & 6 \\
\hline 11 & SMC278CS & $(\mathrm{TG})_{19}(\mathrm{AG})_{25}$ & $\begin{array}{l}\text { TTCTAGTGCCAATCCATCTCAGA } \\
\text { CATGCCAACTTCCAAACAGACT }\end{array}$ & 64 & 8 \\
\hline 12 & SMC24DUQ & $(\mathrm{TG})_{13}$ & $\begin{array}{l}\text { CGCAACGACATATACACTTCGG } \\
\text { CGACATCACGGAGCAATCAGT }\end{array}$ & 64 & 6 \\
\hline 13 & SMC1604SA & $(\mathrm{TGC})_{7}$ & $\begin{array}{l}\text { AGGGAAAAGGTAGCCTTGG } \\
\text { TTCCAACAGACTTGGGTGG }\end{array}$ & 58 & 6 \\
\hline 14 & mSSCIR3 & $(\mathrm{GT})_{28}$ & $\begin{array}{l}\text { ATAGCTCCCACACCAAATGC } \\
\text { GGACTACTCCACAATGATGC }\end{array}$ & 60 & 8 \\
\hline 15 & SMC334BS & $(\mathrm{TG})_{36}$ & $\begin{array}{l}\text { CAATTCTGACCGTGCAAAGAT } \\
\text { CGATGAGCTTGATTGCGAATG }\end{array}$ & 60 & 5 \\
\hline 16 & SMC1751CL & $(\mathrm{TGC})_{7}$ & $\begin{array}{l}\text { GCCATGCCCATGCTAAAGAT } \\
\text { ACGTTGGTCCCGGAACCG }\end{array}$ & 60 & 4 \\
\hline 17 & SMC597CS & $(\mathrm{AG})_{31}$ & $\begin{array}{l}\text { GCACACCACTCGAATAACGGAT } \\
\text { AGTATATCGTCCCTGGCATTCA }\end{array}$ & 64 & 11 \\
\hline 18 & SMC119CG & $(\mathrm{TTG})_{12}$ & $\begin{array}{l}\text { TTCATCTCTAGCCTACCCCAA } \\
\text { AGCAGCCATTTACCCAGGA }\end{array}$ & 58 & 5 \\
\hline 19 & SMC486CG & $(\mathrm{CA})_{34}$ & $\begin{array}{l}\text { GAAATTGCCTCCCAGGATTA } \\
\text { CCAACTTGAGAATTGAGATTCG }\end{array}$ & 58 & 4 \\
\hline 20 & SMC569CS & $(\mathrm{TG})_{37}$ & $\begin{array}{l}\text { GCGATGGTTCCTATGCAACTT } \\
\text { TTCGTGGCTGAGATTCACACTA }\end{array}$ & 62 & 5 \\
\hline 21 & SMC18SA & $(\mathrm{CGA})_{10}$ & $\begin{array}{l}\text { ATTCGGCTCGACCTCGGGAT } \\
\text { AGTCGAAAGGTATAATAGTGTTAC }\end{array}$ & 62 & 5 \\
\hline
\end{tabular}




\section{Data analysis}

The GeneMapper 3.0 software (Applied Biosystems) was used for processing the GeneScan files to reveal the electropherograms. The program calibrated the size of the DNA fragment automatically according to the GeneScan ${ }^{\mathrm{TM}} 500 \mathrm{Rox}^{\mathrm{TM}}$ Size Standard. Those that produced measurable fluorescence peaks with $\mathrm{CE}$ were scored manually. The presence of a particular SSR allele was given a score of "A" and its absence a score of "C." The overall scorings for the 144 SSR alleles in an affixed sequence order that were amplifiable from all the 21 SSR markers for a particular variety constituted its genotyping file as described by Pan et al. (2007). Other DNA fragments that showed measurable, yet inconsistent, fluorescence peaks during CE as a result of "stutters", "pull-ups", "dinosaur tails", or "minus-adenine" were not scored (Pan et al., 2003a). Each genotyping file was manually scored twice to avoid any error. The resulting genotyping files of all 20 varieties were aligned using the Multiple Sequence Alignment program of the DNAMAN ${ }^{\circledR}$ software (Lynnon Biosoft, Vaudreuil, Quebec, Canada) to identify those sequences that were unique for a particular cultivar, to indicate how many cultivars could be identified by a particular SSR marker and also to generate a homology tree. The homology tree was used to analyze the grouping pattern and diversity among the different cultivars (Chen et al., 2009).

The resolving power (RP) of each SSR marker was calculated using the formula given by Prevost and Wilkinson (1999): $\mathrm{RP}=\sum \mathrm{Ib}$, where $\mathrm{Ib}$ represents allele information, which is computed by the formula $\mathrm{Ib}=1-(2 \times|0.5-\mathrm{M}|)$. The $\mathrm{M}$ value is the proportion of the total 20 genotypes containing the allele. On the other hand, the polymorphism information content (PIC) for each SSR marker was calculated using the formula of Smith et al. (1997): PIC = 1 $\sum \mathrm{P} i^{2}$, where $\mathrm{P} i$ is the frequency of the $i$ th allele.

\section{RESULTS}

\section{SSR polymorphic potential}

The 21 SSR markers amplified a total of 144 alleles, of which 135 (93.8\%) were polymorphic. The number of alleles produced by each marker varied from 3 to 11, with an average of 6.85. Markers SMC31CUQ and SMC597CS produced the largest number of alleles, 11, while marker SMC36BUQ produced the smallest number, 3 (Figure 1). The high number of alleles and polymorphic nature of these SSR markers indicated their robustness in fingerprinting sugarcane cultivars. However, the number of alleles amplified by any SSR marker was not directly related to its ability to distinguish the sugarcane cultivars. The number of cultivars distinguishable by any SSR marker varied from zero to twenty. SMC36BUQ did not generate unique binary sequence for any cultivar, so no cultivar could be identified using this primer. In contrast, markers SMC31CUQ, mSSCIR3 and SMC597CS produced 20 different allelic binary sequence combinations, with each sequence combination being unique for a particular cultivar. Therefore, these three SSR markers were capable of discriminating all 20 cultivars studied.

\section{Polymorphism information content}

The PIC values of the 21 SSR markers varied from 0.4 (marker SMC1751CL) to 0.84 


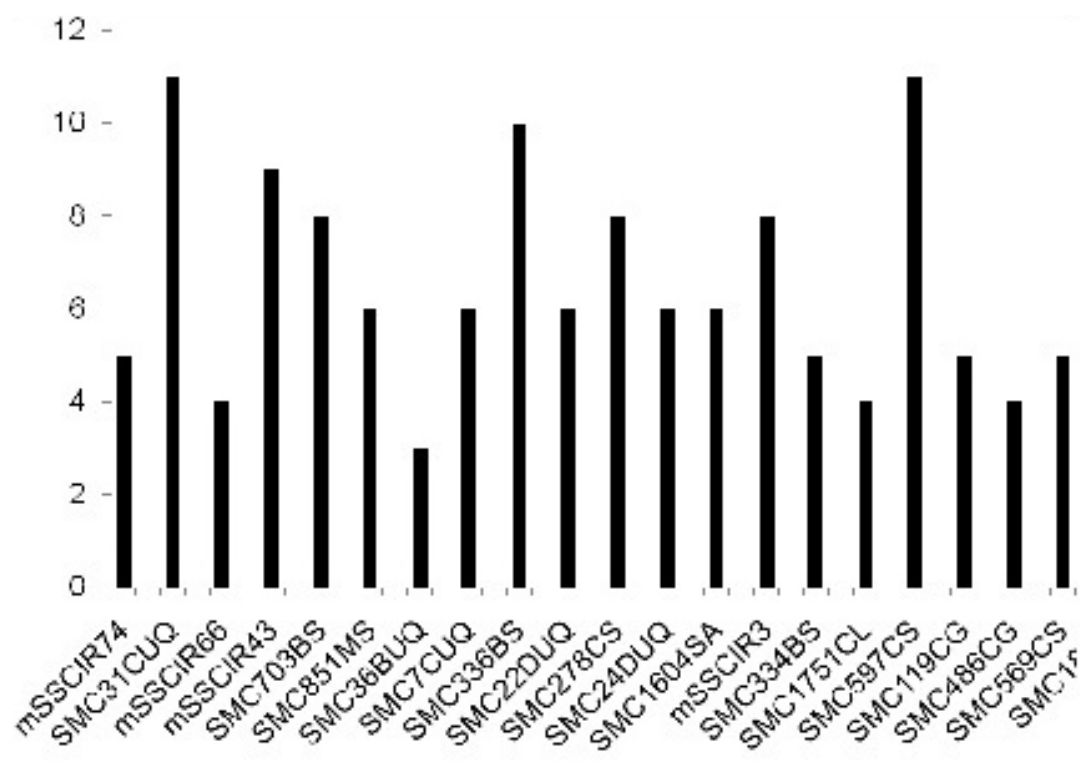

Figure 1. Number of alleles amplified by each marker.

(marker SMC597CS) with a mean of 0.69 (Table 3). Overall, the PIC values from this study were similar to those reported by Pan et al. (2006).

Table 3. SSR numbers and names, their polymorphism information content (PIC), resolving power (RP) of marker, and number of cultivars distinguished by each marker pair.

\begin{tabular}{lllcr}
\hline Number & SSR name & PIC & RP & Number of cultivars distinguished \\
\hline 1 & mSSCIR74 & 0.48 & 1.0 & 5 \\
2 & SMC31CUQ & 0.80 & 5.1 & 20 \\
3 & mSSCIR66 & 0.80 & 0.6 & 6 \\
4 & mSSCIR43 & 0.75 & 3.9 & 16 \\
5 & SMC703BS & 0.46 & 1.3 & 10 \\
6 & SMC851MS & 0.80 & 1.7 & 0 \\
7 & SMC36BUQ & 0.53 & 2.4 & 6 \\
8 & SMC7CUQ & 0.52 & 0.9 & 5 \\
9 & SMC336BS & 0.81 & 4.4 & 14 \\
10 & SMC22DUQ & 0.47 & 2.2 & 11 \\
11 & SMC278CS & 0.82 & 2.6 & 9 \\
12 & SMC24DUQ & 0.79 & 2.8 & 2 \\
13 & SMC1604SA & 0.70 & 2.8 & 2 \\
14 & mSSCIR3 & 0.64 & 4.9 & 2 \\
15 & SMC334BS & 0.72 & 3.1 & 6 \\
16 & SMC1751CL & 0.40 & 0.0 & 2 \\
17 & SMC597CS & 0.84 & 5.0 & 7 \\
18 & SMC119CG & 0.80 & 2.3 & 4 \\
19 & SMC486CG & 0.61 & 1.0 & \\
20 & SMC569CS & 0.73 & 0.8 & \\
21 & SMC18SA & 0.67 & 1.1 & 2 \\
Mean & & 0.69 & 2.37 & \\
Standard deviation & & \pm 0.14 & \pm 1.55 & \\
\hline
\end{tabular}




\section{Resolving power}

Resolving power depended on the distribution of the alleles within genotypes. The RP values ranged from 0.0 (marker SMC1751CL) to 5.1 (marker SMC31CUQ) with a mean of 2.37 (Table 3). Three markers, namely SMC31CUQ, mSSCIR3, and SMC597CS, showed RP values equal to or greater than 4.9, and were able to distinguish all the 20 sugarcane cultivars evaluated in this study. However, the exact number of cultivars distinguishable by any SSR primer pair was not solely correlated with its RP value, but rather a combination of RP, PIC and the number of detectable SSR alleles.

\section{Dendrogram analysis and genetic diversity}

The presence and absence of a particular allele was scored for each of the 20 cultivars, and presence was represented by the symbol A and absence by the symbol C. For example, the molecular identity of variety CPF246 was represented by the following sequence based on the presence and absence of all 144 alleles, AAC CAAACCCAAAA ACCCACCCCAACACCCCCAACACACACACAAACCCAC CACCAACCAACCAAACCACACAAAACCCAACACCACCAACCAAACCCCAAC CAACCCCCACCCCCACCCCCCAAACACCACAACACCCCAAAA. The resulting genotyping files of all 20 varieties were aligned. From these data, a homology tree was constructed by the Multiple Sequence Alignment Program that showed 58 to $79 \%$ similarities among the 20 cultivars (Figure 2). The maximum homology of $79 \%$ was observed between CPD346 and CSSG676. The 20 cultivars clustered into two major groups. Group I consisted of 16 cultivars and could be further divided into two subgroups, group IA and group IB. Group IA comprised SPSG2453, SPF213, NSG311, NSG555, CPF246, HoSG529, and all these cultivars shared $65 \%$ homology. In this group, no red rot-susceptible cultivar was present. The first two cultivars, CPSG2453 and SPF213, are moderately resistant and shared $69 \%$ homology. A maximum homology of $74 \%$ was observed between NSG311 and NSG555, which are respectively highly resistant and moderately resistant. This relatively high similarity is expected, since they are half-siblings. Sixty-seven percent of homology was found between the CPF246 and HoSG529 cultivars, both of them resistant to red rot. Group IB consisted of CPD346, CSSG676, CPD335, CPF237, SPSG26, SPSG79, SPSG394, SPF234, CP77-400, HSF242, and these cultivars showed 66\% homology. The first half of Group IB from CPD346 to SPF234 displayed 67\% homology, and included two susceptible to red rot cultivars (SPSG394, SPF234), two moderately resistant (CPD335, CPD346), two resistant (SPSG26, SPSG79), and two highly resistant (CSSG676, CPF237). The genotypes SPSG26 and SPSG79, which were the progeny of reciprocal crosses, and SPSG394, which shared a common genitor with SPSG26 and SPSG79, were altogether in subgroup IB. The second half of Group IB was constituted by cultivars CP77-400 and HSF242, respectively, resistant and susceptible to red rot. The homology between them was $71 \%$. Group II consisted of four genotypes, namely Co1148, CPD334, HSF240, and NSG59, showing 67\% homology. Co1148 is susceptible to red rot, while the three other genotypes are resistant or highly resistant. 


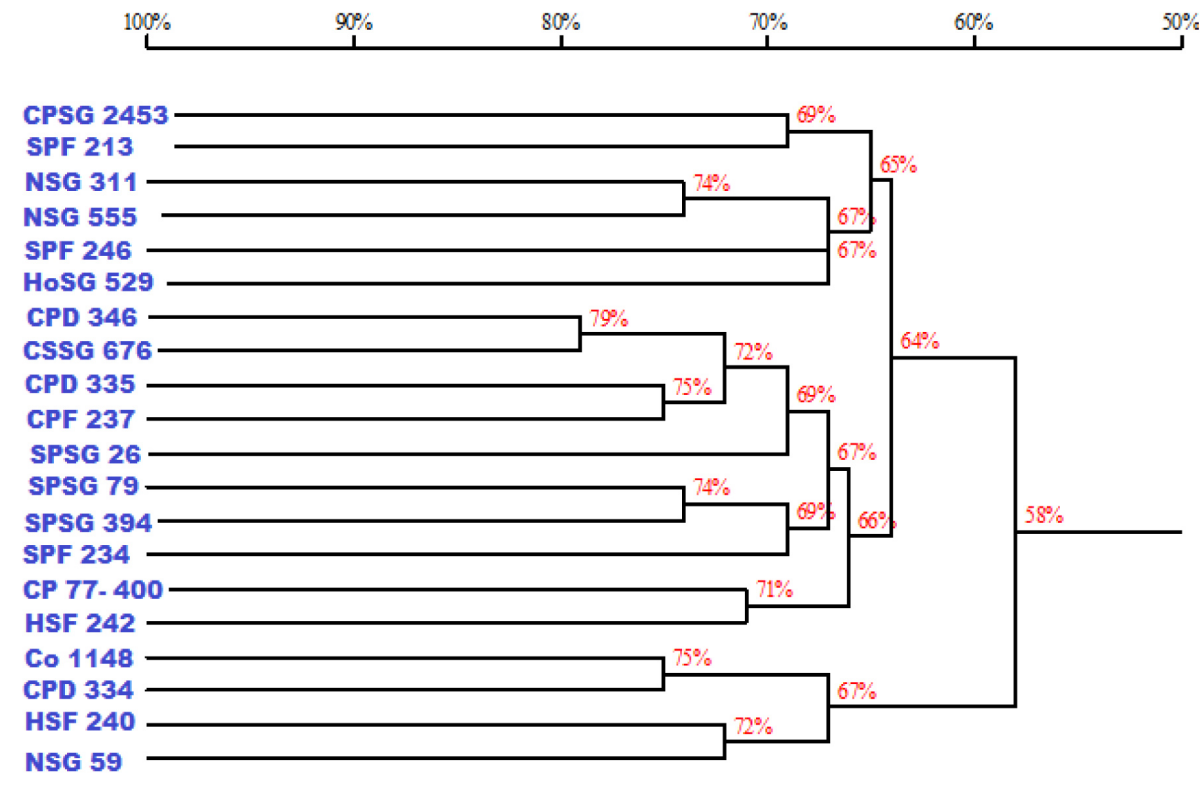

Figure 2. Homology tree of 20 sugarcane cultivars.

\section{DISCUSSION}

It has been shown that RAPD and AFLP molecular markers have sufficient discriminatory power to distinguish different cultivars; nonetheless, these molecular tools often fail to reach clear conclusions in identifying duplicated clones (Zhang et al., 2006). SSR markers have been widely used in molecular genotyping and genetic diversity analysis of sugarcane because of their locus-specificity and polymorphic nature (Cordeiro et al., 2000; Pan et al., 2003a, 2006; Glynn et al., 2009).

PIC and RP have been used in several studies (Smith et al., 1997; Prevost and Wilkinson, 1999; Korkovelos et al., 2008) to analyze markers for their informativeness in genotyping, genetic diversity assessment, and discriminatory power. However, having high values of PIC and RP alone does not always indicate that an SSR marker can be efficiently used when genotyping sugarcane cultivars. The same is true in the case of the total number of detectable alleles. Only when all the three parameters are considered together, can one see the screening power of a particular SSR marker and select a small number of SSR markers to effectively detect the extent of genetic diversity among sugarcane cultivars, which is what was observed in this study.

In the current research, markers with higher RP values were more informative and could identify more cultivars. SSRs with RP value equal to or greater than 4.9 were able to discriminate all 20 cultivars. These results are in agreement with Prevost and Wilkinson (1999), who observed a strong linear relationship between resolving power and discriminatory power of a marker. However, these values are dynamic and changeable, depending upon the number and nature of the genetic material involved. Although PIC values may serve as a reference in detecting genetic variability between genotypes, extra information is needed to proceed with 
marker selection. A higher PIC value does not guarantee a high efficiency to differentiate between cultivars. SSR markers that show higher PIC values and produce a larger number of detectable alleles can distinguish a greater number of cultivars than SSR markers with higher PIC values but producing smaller numbers of detectable alleles. For example, SMC31CUQ and mSSCIR66 shared the same PIC value of 0.80, but SMC31CUQ could amplify up to 11 detectable alleles and was able to identify all the 20 cultivars involved in this study. On the other hand, mSSCIR66 produced up to four amplifiable alleles and was able to differentiate only six cultivars. Thus, PIC value along with other parameters should be considered for primer selection.

The dendrogram showed that there was a high degree of similarity among the cultivars analyzed. The assignment of 16 of $20(80 \%)$ genotypes in one cluster is indicative of the narrow genetic base of these sugarcane cultivars, which means that most of these cultivars may share the same genetic background, based on common ancestors. Three of four red rot susceptible cultivars (Co1148, HSF242, SPSG394, and SPF234) were present in one group (GI) and they were closely related.

From a general point of view, the findings of this study will help cane breeders correctly identify cultivars and expand the genetic base of the sugarcane by making crosses between genotypes that are less related. Crosses could then be selected and propagated to bring positive results to the sugarcane crop, keeping in mind that this is one of the most important crops grown in Pakistan. The 21 SSR markers analyzed can produce a large amount of polymorphism among the 20 cultivars. Three of these markers, namely SMC31CUQ, mSSCIR3, and SMC597CS, were identified as being able to discriminate the 20 sugarcane cultivars studied, currently grown in Pakistan.

\section{ACKNOWLEDGMENTS}

Research was part of the Ph.D. thesis of U. Hameed that was conducted at the United States Department of Agriculture, Agricultural Research Service, Mid-South Area, Sugarcane Research Laboratory in Houma, LA, USA. Under a Pakistan-U.S. Science and Technology Cooperative Program. Sheron Simpson performed the high-throughput PCR and CE process at the USDA-ARS, MSA Genomics Laboratory directed by Dr. Brian E. Scheffler.

\section{REFERENCES}

Brown JS, Schnell RJ, Power EJ, Douglas SL, et al. (2007). Analysis of clonal germplasm from five Saccharum species: S. barberi, S. robustum, S. officinarum, S. sinense and S. spontaneum. A study of inter- and intraspecies relationships using microsatellite markers. Genet. Res. Crop Evol. 54: 627-648.

Chen PH, Pan YB, Chen RK and Xu LP (2009). SSR marker-based analysis of genetic relatedness among sugarcane cultivars (Saccharum spp. hybrids) from breeding programs in China and other countries. Sugar Tech. 11: 347-354.

Chen X, Temnykh S, Xu Y and Cho YG (1997). Development of a microsatellite framework map providing genome-wide coverage in rice (Oryza sativa L.). Theor. Appl. Genet. 95: 553-567.

Cordeiro GM, Taylor GO and Henry RJ (2000). Characterisation of microsatellite markers from sugarcane (Saccharum sp.), a highly polyploid species. Plant Sci. 155: 161-168.

Cordeiro GM, Pan YB and Henry RJ (2003). Sugarcane microsatellites for the assessment of genetic diversity in sugarcane germplasm. Plant Sci. 165: 181-189.

D'Hont A, Grivet L, Feldmann P, Rao S, et al. (1996). Characterisation of the double genome structure of modern sugarcane cultivars (Saccharum spp.) by molecular cytogenetics. Mol. Gen. Genet. 250: 405-413.

Doyle JJ and Doyle JL (1990). Isolation of plant DNA from fresh tissue. Focus 12: 13-15.

Garcia AA, Kido EA, Meza AN and Souza HM (2006). Development of an integrated genetic map of a sugarcane 
(Saccharum spp.) commercial cross, based on a maximum-likelihood approach for estimation of linkage and linkage phases. Theor. Appl. Genet. 112: 298-314.

Glynn NC, Mccorkle K and Comstock JC (2009). Diversity among mainland USA sugarcane cultivars examined by SSR genotyping. Am. Soc. Sugar Cane Technol. 29: 36-52.

Goldstein DB and Schlotterer C (1999). Microsatellites: Evolution and Applications. Oxford University Press, Oxford.

Harvey M and Botha FC (1996). Use of PCR-based methodologies for the determination of DNA diversity between Sacchrum varieties. Euphytica 89: 257-265.

Hoarau JY, Grivet L, Offmann B, Raboin LM, et al. (2002). Genetic dissection of a modern sugarcane cultivar (Saccharum spp.). II. Detection of QTLs for yield components. Theor. Appl. Genet. 105: 1027-1037.

Jannoo N, Grivet L, Seguin M and Paulet F (1999). Molecular investigation of the genetic base of sugarcane cultivars. Theor. Appl. Genet. 99: 171-184.

Jeffreys AJ, Wilson V and Thein SL (1985). Individual-specific 'fingerprints' of human DNA. Nature 316: 76-79.

Korkovelos AE, Mavromatis AG, Huang WG, Hagidimitriou M, et al. (2008). Effectiveness of SSR molecular markers in evaluating the phylogenetic relationships among eight Actinidia species. Sci. Hortic. 116: 305-310.

Lima ML, Garcia AA, Oliveira KM, Matsuoka S, et al. (2002). Analysis of genetic similarity detected by AFLP and coefficient of parentage among genotypes of sugar cane (Saccharum spp.). Theor. Appl. Genet. 104: 30-38.

Liu ZW, Biyashev RB and Saghai-Maroof MA (1996). Development of simple sequence repeat DNA markers and their integration into a barley linkage map. Theor. Appl. Genet. 93: 869-876.

$\mathrm{Lu}$ YH, D'Hont A, Paulet F and Grivet L (1994). Molecular diversity and genome structure in modern sugarcane varieties. Euphytica 78: 217-226.

Miller JD, Glaz B, Tai PYP, Comstock JC, et al. (2005). Genetic contribution to yield gains in the Florida sugarcane industry across 33 years. Crop Sci. Am. 45: 92-97.

Nair NV, Selvi A, Sreenivasn TV and Pushpalatha KN (2002). Molecular diversity in Indian sugarcane cultivars as revealed by random amplified DNA polymorphism. Euphytica 127: 219-225.

Pan YB, Cordeiro GM, Richard Jr EP and Henry RJ (2003a). Molecular genotyping of sugarcane clones with microsatellite DNA markers. Maydica 48: 319-329.

Pan YB, Miller JD, Schnell RJ and Richard J (2003b). Application of microsatellite and RAPD fingerprints in the Florida sugarcane variety program. Sugar Cane Int. 19-28.

Pan YB, Tew TL, Schnell RJ and Viator RP (2006). Microsatellite DNA marker-assisted selection of Saccharum spontaneum cytoplasm-derived germplasm. Sugar Tech. 8: 23-29.

Pan YB, Scheffler BS and Richard JEP (2007). High-throughput genotyping of commercial sugarcane clones with microsatellite (SSR) DNA markers. Sugar Tech. 9: 176-181.

Pestsova E, Ganal MW and Roder MS (2000). Isolation and mapping of microsatellite markers specific for the D genome of bread wheat. Genome 43: 689-697.

Pinto LR, Oliveira KM, Marconi T and Garcia AAF (2006). Characterization of novel sugarcane expressed sequence tag microsatellites and their comparison with genomic SSRs. Plant Breed. 125: 378-384.

Pinto LR, Leite DC, Favero TM, Pastina MM, et al. (2011). Identification of microsatellites markers associated with yield components and quality parameters in sugarcane. Int. Sugar J. 113: 56-60.

Piperidis G, Taylor GO and Smith GR (2001). A microsatellite marker database for fingerprinting sugarcane clones. XXIV Proc. Int. Soc. Sugar Cane Technol.632-633.

Powell W, Machray GC and Provan J (1996). Polymorphism revealed by simple sequence repeats. Trends Plant Sci. 1: 215-222.

Prevost A and Wilkinson MJ (1999). A new system of comparing PCR primers applied to ISSR fingerprinting. Theor. Appl. Genet. 98: 107-112.

Sambrook J, Fritsch EF and Maniatis T (1989). Molecular Cloning. A Laboratory Manual. Cold Spring: Harbor Laboratory Press, New York.

Sharopova N, McMullen MD, Schultz L, Schroeder S, et al. (2002). Development and mapping of SSR markers for maize. Plant Mol. Biol. 48: 463-481.

Silva J and Bressiani J (2005). Sucrose synthase molecular marker associated with sugar content in elite sugarcane progeny. Genet. Mol. Biol. 28: 294-298.

Singh RK, Singh P, Misra P and Singh SP (2005). STMS marker for tagging high sugar genes in sugarcane. Sugar Tech. 7: 74-76.

Smith JSC, Chin ECL, Shu H, Smith OS, et al. (1997). An evaluation of the utility of SSR loci as molecular markers in maize (Zea mays L.): comparisons with data from RFLPs and pedigree. Theor. Appl. Genet. 95: 163-173.

Zhang D, Mischke S, Goenaga R and Hemeida AA (2006). Accuracy and reliability of high-throughput microsatellite genotyping for Cacao clone identification. Crop Sci. 46: 2084-2092.

Genetics and Molecular Research 11 (2): 1195-1204 (2012)

CFUNPEC-RP www.funpecrp.com.br 